This is the accepted version of the following article: Sacchi, S., Rusconi, P., Bonomi, M., \& Cherubini, P. (2014). Effects of asymmetric questions on impression formation: A trade-off between evidence diagnosticity and frequency. Social Psychology, 45(1), 41-53. doi: 10.1027/18649335/a000158, (c) 2014 by Hogrefe Publishing.

This article may not exactly replicate the final version published in Social Psychology. It is not the version of record and is therefore not suitable for citation.

This article has been published in final form at:

http://www.psycontent.com/content/b43tv0375g551222/?p=bfbb4a054f0448ec89951

$\underline{146 \mathrm{dc} 84 \mathrm{e} 5 \mathrm{~cd} \& \mathrm{pi}=3}$ 
Running Head: ASYMMETRY AND IMPRESSION FORMATION

Effects of asymmetric questions on impression formation:

A trade-off between evidence diagnosticity and frequency

Simona Sacchi, Patrice Rusconi, Mattia Bonomi, Paolo Cherubini

Department of Psychology, University of Milano-Bicocca, Italy

Author's note:

The present research was funded by PRIN 2008, granted to Paolo Cherubini by the Italian Department of Education, University and Research (MIUR).

The authors thank Costanza Riccioli for her help in collecting data.

Correspondence concerning this article should be addressed to Simona Sacchi, Department of Psychology, University of Milano-Bicocca, P.zza dell'Ateneo Nuovo 1, 20126, Milano, Italy. e-mail: simona.sacchi@unimib.it. Phone ++39-02-64483821 
Running Head: ASYMMETRY AND IMPRESSION FORMATION

Effects of asymmetric questions on impression formation:

A trade-off between evidence diagnosticity and frequency 


\begin{abstract}
When examining social targets, people may ask asymmetric questions, that is, questions for which "yes" and "no" answers are neither equally diagnostic nor equally frequent. The consequences of this information-gathering strategy on impression formation deserve empirical investigation. The present work explored the role played by the trade-off between the diagnosticity and frequency of answers that follow asymmetric questions. In Study 1, participants received answers to symmetric/asymmetric questions on an anonymous social target. In Study 2, participants read answers to a specific symmetric/asymmetric question provided by other group members. Overall, the results of both studies indicate that asymmetric questions had less impact on impressions than did symmetric questions, suggesting that individuals are more sensitive to data frequency than diagnosticity when forming impressions.
\end{abstract}

Keywords: hypothesis testing, asymmetry, diagnosticity, confirmation bias 


\section{Effects of asymmetric questions on impression formation:}

\section{A trade-off between evidence diagnosticity and frequency}

When we develop initial impressions of unknown others, we can observe their attitudes and behaviors in their social context or we can ask questions to obtain additional information (e.g., Snyder \& Swann, 1978). Despite the ecological relevance of the social hypothesis-testing process, people might be prone to inefficiencies while searching for new evidence that causes them to perceive their prior assumptions (i.e., hypotheses) as more (or less) likely than they actually are (e.g., McKenzie, 2004; Nickerson, 1998; Trope \& Liberman, 1996). Such an unwarranted confidence in the hypothesis being tested (i.e., the focal hypothesis) has been termed confirmation bias (e.g., Klayman, 1995; McKenzie, 2004; Nickerson, 1998). Confirmation bias would emerge not only in the way in which people evaluate incoming data but also in the previous stage of the impression-formation process, namely, information gathering, which is when people may seek onesided information that is partial to initial assumptions (Nickerson, 1998).

The main purpose of the present study is to investigate the effects of a particular information search strategy, i.e., the asymmetric strategy (Cameron \& Trope, 2004; Trope \& Thompson, 1997), on impression formation. Gathering information on social targets asymmetrically entails asking queries for which affirmative and negative replies have different effects on judgment and impression formation. Thus, for example, discovering that a person previously spent time in prison easily leads us to think him/her to be dishonest, whereas we do not necessarily judge a person as honest if we know that he/she was never in prison. We aim to analyze the relationship between exposure to answers obtained through asymmetric questions and the tendency to confirm a social hypothesis. More specifically, our interest is in clarifying the effect of the diagnosticities of "yes" and "no" answers to a question on people's judgments compared to the effect of the number of "yes" and "no" answers. Indeed, under some circumstances, asymmetric questions entail a trade-off between diagnosticity and frequency, whereby answers that occur frequently are less diagnostic than rare answers (e.g., McKenzie, 2006; Poletiek, 2001, Chaps. 1 and 2; Poletiek \& Berndsen, 
2000; Rusconi, Sacchi, Toscano, \& Cherubini, 2012). Because it is unknown whether people base their judgments more on highly diagnostic (but rare) answers than on highly frequent (but poorly diagnostic) answers or vice versa, the present work aims to explore the presence and the effect of a cognitive trade-off between diagnosticity and frequency when an asymmetric information search strategy is implied.

\section{Asymmetry and confirmation bias}

Prior research using the 'social hypothesis-testing paradigm' (Snyder \& Swann, 1978) has revealed that people generally ask the respondent about features that are consistent with their a priori belief and expectancies while conducting interviews (e.g., Bassok \& Trope, 1984; Dardenne \& Leyens, 1995; Devine, Hirt, \& Gehrke, 1990; Trope \& Bassok, 1983; Van Avermaet, 1988; Yzerbyt \& Leyens 1991). Hence, people generally ask questions such as, “Are you talkative?” while exploring if somebody else is warm rather than questions such as, "Do you like being alone?" Despite initial claims (e.g., Snyder \& Swann, 1978; Wason, 1960), seeking features that are expected to be present under the focal hypothesis more than under the alternate (i.e., positive testing) is now widely considered a question-asking strategy that, by itself, is insufficient to lead to confirmation bias (e.g., Klayman, 1995; Klayman \& Ha, 1987; McKenzie, 2004; Fiedler \& Walther, 2004). In fact, one can receive hypothesis-disconfirming answers (e.g., "No, I am not talkative") to positive questions, thus weakening the confidence in the focal hypothesis (Kayman \& Ha, 1987).

More recently, social cognitive studies have suggested that confirmation bias occurs when an asymmetric strategy is used (Cameron \& Trope, 2004; Trope \& Thompson, 1997). Asymmetric questions are queries for which "yes" and "no" answers differ with respect to their diagnosticity (e.g., Cameron \& Trope, 2004; Cherubini, Rusconi, Russo, Di Bari, \& Sacchi, 2010; Trope \& Thompson, 1997). For example, one might inquire about a new acquaintance's courage by asking "Has s/he ever risked her/his life to save somebody else?". This is an asymmetric-confirming question because the hypothesis-confirming yes-answer strongly supports the hypothesis of the 
target's bravery, but a no-answer does not falsify it to the same extent (a person may be courageous without necessarily being a hero). In Bayesian terms, a question is asymmetric confirming whenever the following equation applies:

$$
|p(H)-p(H \mid D+)|>|p(H)-p(H \mid D-)|
$$

where $\mathrm{p}(\mathrm{H})$ is the a priori estimated probability of the hypothesis, $\mathrm{p}(\mathrm{H} \mid \mathrm{D}+)$ is the estimated probability that the hypothesis $(\mathrm{H})$ is true given confirming evidence to the question $(\mathrm{D}+)$, and $\mathrm{p}(\mathrm{H} \mid \mathrm{D}-)$ is the estimated probability that the hypothesis is true given disconfirming evidence (D-) (see Sacchi, Rusconi, Russo, Bettiga, \& Cherubini, 2012).

Conversely, asking "Is s/he even afraid of staying at home alone?" to test someone's courage implies an asymmetric-disconfirming strategy because the hypothesis-disconfirming yesanswer (D-) is more diagnostic than the hypothesis-confirming no-answer (D+), that is: $|p(H)-p(H \mid D+)|<|p(H)-p(H \mid D-)|$. “Is s/he worried about going to the dentist?” is an example of a symmetric question in which "yes" and "no" answers are equally diagnostic: A yesanswer confirms the courage hypothesis as much as the no-answer supports the lack of courage hypothesis; that is, $|p(H)-p(H \mid D+)|=|p(H)-p(H \mid D-)|$.

It has been argued that people can preserve their prior assumptions through asymmetric testing. This argument rests on the idea that the asymmetry in diagnosticity between "yes" and "no" answers following asymmetric queries allows people to limit their exposure to disconfirming information, whenever they ask questions for which the confirming answer is more diagnostic than the disconfirming answer. In particular, recent social-cognitive research has suggested that strong pre-existing expectations (e.g., stereotypes) can lead people to look asymmetrically for information (Brambilla, Rusconi, Sacchi, \& Cherubini, 2011; Cameron \& Trope, 2004; Sacchi et al., 2012; Trope \& Thompson, 1997). Specifically, it has been shown that people tend to ask more asymmetric-confirming questions when the target of their question is a member of a stereotyped group (Cameron \& Trope, 2004; Trope \& Thompson, 1997). The combination of the perceived high 
frequency resulting from stereotype-based beliefs with the high diagnosticity of the confirming answer resulting from the asymmetry of the question would bias people toward the preservation of their prior expectations (e.g., Trope \& Thompson, 1997). In other words, the acquisition of new, individuating information might not always reduce stereotype-based beliefs but can foster the maintenance and consolidation, even polarization, of people's initial opinions. For example, asking "Have you ever been in prison?" to an out-group member (e.g., an immigrant) in order to inquire about her/his dishonesty would entail anticipating a highly diagnostic, hypothesis-confirming answer (i.e., the "yes" answer), thus leading to confirmation of the focal hypothesis (i.e., dishonesty). Indeed, the confirming answer ("yes") would be more diagnostic than the disconfirming answer ("no") because one might have not been in prison but still exhibit other dishonest behaviors. Furthermore, the stereotype-based expectations would increase the subjective probability (i.e., the perceived frequency) of receiving the confirming answer. For these reasons, some authors argue that an asymmetric information search leads to confirmation bias whenever strong a priori beliefs (e.g., stereotypes) underlie the search for information (e.g., Trope \& Thompson, 1997). Under these circumstances, the strong a priori beliefs, $\mathrm{p}(\mathrm{H})$, would lead testers to perceive the hypothesis-confirming answer to an asymmetric question as both highly frequent and highly diagnostic.

\section{The trade-off between diagnosticity and frequency in answers}

Although previous research has tended to interpret the asymmetric search in terms of confirmation bias (e.g., Trope \& Thompson), the relationship between this strategy and its consequences on the impression-formation process could be more nuanced than suggested by previous studies. In fact, from a Bayesian perspective, whenever the focal hypothesis has the same a priori probability as its alternative (i.e., in the absence of strong a priori beliefs), the use of an asymmetric strategy when gathering information implies a trade-off between the diagnosticity and frequency of the anticipated answers (e.g., McKenzie, 2006; Poletiek, 2001; Poletiek \& Berndsen, 2000; Rusconi et al., 2012). The crucial point is that when people ask asymmetric queries, they look 
for highly diagnostic but rare information. A confirming answer to an asymmetric-confirming question strongly supports the focal hypothesis but is exceptional, whereas a disconfirming answer is not decisive but is common (Poletiek \& Berndsen, 2000). Hence, if we obtain a yes-answer from a new acquaintance to the question "Have you ever risked your life to save somebody else?", we could be reasonably sure that our interlocutor is a courageous person. However, it is also unlikely that a person would answer "yes" to a question about such an extreme behavior. Therefore, the high quality of the evidence is obtained at the expense of the high risk of not finding it. The converse is true for asymmetric-disconfirming questions; hypothesis-disconfirming evidence is highly diagnostic but rare, whereas hypothesis-confirming evidence is not very diagnostic but is common. Accordingly, unlike symmetric questions, asymmetric questions imply that highly frequent answers have less diagnostic value than highly infrequent answers whenever the prior probability of the focal hypothesis is not extreme; that is, when our knowledge about the target of our questions is limited or when we do not have stereotype-consistent expectations (e.g., McKenzie, 2006; Poletiek, 2001; Poletiek \& Berndsen, 2000). It is worth emphasizing that, theoretically, diagnosticity and frequency are independent and that the trade-off is not certain to occur, as illustrated above for circumstances in which stereotypes influence the testers' information search (e.g., Trope \& Thompson, 1997). For instance, when $\mathrm{p}(\mathrm{H})$ (i.e., the prior probability of the focal hypothesis) is very high, a confirming piece of evidence could be very diagnostic as well as very frequent. Hence, if the question "Have you ever risked your life to save somebody else?" is asked among a team of fire-fighters, a yes-answer will not be as rare as in the general population (e.g., Trope \& Thompson, 1997). However, when people do not have strong a priori expectations and the prior probability of the focal hypothesis is approximately $p=0.5$ (as in the case of information searching about unknown persons or about non-stereotyped social targets), a frequent outcome (e.g., an answer that occurs commonly, a frequent test result) is less diagnostic than an infrequent outcome from a Bayesian perspective (e.g., McKenzie, 2006; Poletiek, 2001; Poletiek \& Berndsen, 2000). Note that 
the trade-off between diagnosticity and frequency always occurs whenever the degree of asymmetry of questions $(A)$ is calculated using the aforementioned formula; that is,

$$
A=|p(H)-p(H \mid D+)|-|p(H)-p(H \mid D-)| \text {. }
$$

When $\mathrm{p}(\mathrm{H})$ is approximately 0.5 , this definition does not admit a condition of high asymmetry, high diagnosticity and high frequency.

Previous research has already explored the consequences of the trade-off between diagnosticity and frequency that are implied by the asymmetric information search on information seeker's expectations (Rusconi et al., 2012). Specifically, this study investigated the responses that people expected to receive and the likelihood of such expected responses when an asymmetric (vs. a symmetric) strategy is adopted. The present contribution was aimed at extending this previous work by exploring the role of the frequency/diagnosticity trade-off on final impression formation and hypothesis validation when the answers are obtained. In fact, investigating whether the asymmetric information seeker is more influenced by evidence diagnosticity rather than by its frequency becomes crucial when disentangling the association between asymmetry and confirmation bias.

Classical studies on hypothesis testing have underlined individuals' sensitivity to the frequency rather than diagnosticity of confirmatory clues (e.g., Skov \& Sherman, 1986; Slowiaczek, Klayman, Sherman, \& Skov, 1992). For example, Skov and Sherman (1986) and Slowiaczek et al. (1992) found that people prefer to ask questions about features whose probability is high (i.e., $p(D+)>0.5)$ to confirm the focal hypothesis. Similarly, previous studies used a frequency-based argument to account for some illusions in social contexts. For example, it has been argued that illusory correlations might stem more likely from the skewed frequency distributions of the observations presented to participants rather than from the distinctiveness that characterizes rare observations (e.g., Fiedler, 1991, 1996). 
However, other studies have revealed people's tendencies to maximize the diagnosticity of the acquired information in more contextualized tasks (e.g., Poletiek \& Berndsen, 2000). In other words, in tasks using less abstract materials than those used by Skov and Sherman (1986), people would prefer to ask questions about features that are not so likely to confirm the focal hypothesis (i.e., $p(D+)<0.5)$ but whose diagnosticity is high. In their information gain theory, Oaksford and Chater (1994) suggested that hypothesis testers search for information to provide the greatest "expected information gain" in deciding between two hypotheses (i.e., diagnosticity). Moreover, according to this perspective, the rarer the piece of information, the more informative it is (see also Tribus, 1961).

Given the presence of these different approaches in the literature, the present study was devised to address whether people base their inferences on the frequency of obtained evidence or its diagnosticity when inquiring about social targets following asymmetric testing. The issue is relevant because if people are more influenced in their judgments by the diagnosticity than the frequency of the obtained evidence (Fiske, 1980), then the consequences of asymmetric-confirming questions could be interpreted in terms of confirmation bias, as it has usually been conceived by social cognitive research (e.g., Cameron \& Trope, 2004; Trope \& Thompson, 1997). That is, asymmetric-confirming questions would lead to hypothesis confirmation because the hypothesisconfirming answers to these questions are more diagnostic than the hypothesis-disconfirming answers. Moreover, hypothesis-disconfirming queries would lead to hypothesis falsification because the hypothesis-disconfirming answers to these questions are more diagnostic than the hypothesis-confirming answers. In contrast, if people are more sensitive to the frequency of the collected information than to its diagnosticity (e.g., Skov \& Sherman, 1986; Slowiaczek et al., 1992), then the use of asymmetric-confirming questions would result in a paradoxical disconfirmation of the hypothesis being tested. Indeed, in this case, the more frequent, disconfirming answer would have a greater impact on impressions than the more diagnostic, confirming answer following asymmetric-confirming queries. Furthermore, a third alternative 
outcome is theoretically possible: People might be able to balance the diagnosticity and frequency of the expected answers to asymmetric questions. Hence, highly diagnostic but rare yes-answers would be compensated by several uninformative no-answers, and the use of an asymmetric information search strategy would not lead to systematic bias. Thus, this third alternative hypothesis predicts that people's judgments would not be shifted toward either hypothesis confirmation or hypothesis falsification, and the obtained evidence (e.g., the answers to a question) would have a null effect.

\section{Overview of the studies}

In two preliminary studies, we tested sets of questions to select appropriate material for the experiments. Then, in two studies, we addressed the relationship between the use of asymmetric testing in social hypothesis testing and confirmation bias. In Study 1, we examined how people assessed the probability for a person to have a personality trait in light of either a set of symmetric questions or a set of asymmetric questions and the relative "yes"/ "no" answers from the target. Furthermore, we investigated the role played by asymmetry in the hypothesis-testing process both under confirmation and falsification conditions when, from a normative perspective, the evidence would lead to either supporting or refuting a hypothesis. In Bayesian terms, we analyzed how the a priori estimated probability of the hypothesis (i.e., $\mathrm{p}(\mathrm{H})$ ) was revised when confirming evidence $(\mathrm{D}+)$ to the formulated question was provided (i.e., $\mathrm{p}(\mathrm{H} \mid \mathrm{D}+))$ and how it changed when disconfirming evidence (D-) was provided (i.e., $\mathrm{p}(\mathrm{H} \mid \mathrm{D}-)$ )).

In Study 2, we applied the same rationale but changed the procedure (Slowiaczek et al., 1992, Experiments 2A, 2B, and 2C). Participants were presented with the same a/symmetric question asked to different members of the same category who provided different "yes"/"no" answers. The second experiment analyzed how people judged the probability of a member of the category having a specific trait and their willingness to generalize the trait from the sample to the entire social category. In both studies, the frequency and diagnosticity of the answers to the 
a/symmetric questions were pre-tested and varied to obtain sets that were balanced with respect to total diagnosticity, that is, the sum of the diagnosticities of the single answers.

\section{Preliminary Studies}

\section{Participants}

A total of 86 undergraduate students at the University of Milano-Bicocca were approached in university libraries. Thirty-six participants answered the first questionnaire $(60 \%$ women and $40 \%$ men; $\left.M_{a g e}=27.83, S D_{a g e}=7.79\right)$, and fifty participants answered the second questionnaire (70\% women and $30 \%$ men; $\left.M_{a g e}=23.53, S D_{a g e}=2.44\right)$. All participants were Italian.

\section{Materials and procedure}

In the first preliminary study, participants were required to formulate questions to judge whether a person had a personality trait. More specifically, the participants were required to freely generate a series of questions that they would deem useful to ask in order to determine the level at which an anonymous social target actually possessed the selected characteristics (i.e., rigidity, cheerfulness, creativity, untrustworthiness). The initial set of traits were chosen on the basis of the results of previous studies (see Sacchi et al., 2012) and because they were proven not to be associated with strong a priori expectations $(\mathrm{p}(\mathrm{H})$ is approximately 0.5$)$. The following additional instructions were given: Participants were not allowed to ask directly about the target's attribute but had to formulate as many questions as possible and no fewer than three, and all questions had to be answerable in a yes/no format (for a similar procedure, see Trope \& Thompson, 1997). The order of traits was randomly set. Through this procedure and by eliminating bizarre questions and redundancy, we obtained a set of 120 questions (30 questions per trait).

To select the appropriate experimental material for the second preliminary study, we measured the degree of a/symmetry of the questions generated and the diagnosticity of the corresponding "yes" and "no" answers. To this end, the second sample of participants was asked to make inferences regarding the traits after being provided with the questions produced by the participants and the corresponding answers (for a similar procedure, see Trope \& Thompson, 1997). 
Thus, for example, if the participant's question to estimate the target's creativity was "Does he like colors?", participants in the second preliminary study were asked to assess the a priori likelihood for a person in general to be creative $(\mathrm{p}(\mathrm{H}))$, the likelihood for a person who likes colors to be creative $(p(H \mid D+))$, and the likelihood for a person who does not like colors to be creative $(p(H \mid D-$ )). Participants answered the questions on an 11-point scale ranging from $0 \%$ (impossible) to $100 \%$ (certain).

\section{Results}

On the basis of the participants' estimates, the a/symmetry of each question $(A)$ was calculated using the following formula (see Sacchi et al., 2012):

$$
A=|p(H)-p(H \mid D+)|-|p(H)-p(H \mid D-)| \text {. }
$$

Hence, the asymmetry index was determined as a difference of cue validities by subtracting the impact of the disconfirming answer with respect to the priors from the impact of the confirming answer.

We computed the questions' asymmetry indices for each of the 50 participants involved in the second preliminary study and then compared the asymmetry index of each question with 0 (which indicates perfect symmetry) through a series of one-sample $t$-tests. We classified each question as symmetric when its asymmetry index did not differ from 0 ( $p s>.05)$, asymmetricconfirming when the index was significantly higher than $0(p s<.05)$, and asymmetricdisconfirming when the index was significantly lower than $0(p s<.05)$.

Then, the diagnosticity of the "yes" and "no" answers to each question was assessed through a simplified version of the answer diagnosticity formula (Nelson, 2005, 2008). The diagnosticity of a confirming-answer was computed as:

$$
p(H \mid D+)-p(H)
$$

Similarly, the diagnosticity of a disconfirming answer was computed as:

$$
p(H \mid D-)-p(H)
$$


We ensured that participants' estimates of $\mathrm{p}(\mathrm{H})$ of creativity and cheerfulness were moderate and close to 0.5 . More explicitly, $\mathrm{p}($ creative $)=.47$ and $\mathrm{p}($ cheerful $)=.52$. Given these values, the hypothesized trade-off between response frequency and response diagnosticity necessarily occurs from a Bayesian perspective.

Finally, we selected sets of symmetric, asymmetric-confirming, and asymmetricdisconfirming questions and fixed the number of "yes" and "no" answers that participants would have received by ensuring that the total diagnosticity was balanced between sets. Table 1 reports the materials and relative indices selected for Study 1; Table 2 reports the questions and indices selected for Study 2. Note that we used only two traits (creativity and cheerfulness) because we failed to satisfactorily balance the materials for the other items.

\section{Study 1}

\section{Participants}

A total of 97 undergraduate students at the University of Milano-Bicocca volunteered to participate in the study. The sample consisted of $64.9 \%$ women and $35.1 \%$ men, ranging in age from 18 to $48(M=21.82, S D=3.46)$. All participants were Italian citizens.

\section{Material and procedure}

Participants were approached in various libraries at the University of Milano-Bicocca and invited to participate in a study about social perception. Those who accepted were given a questionnaire to fill out. On the cover page, personal data were collected from the participant.

The task consisted in judging to what extent a specific but completely anonymous individual (Mister X) was creative and to what extent a second individual (Mister Y) was cheerful. It should be noted that we used ordinary traits (i.e., creativity and cheerfulness whose $p(H)$ is not likely to be extreme (that is, not far removed from 0.5). In fact, participants' estimates of the prior probability of possessing these traits fluctuated around $p=0.5$, as described above. Moreover, unlike previous studies on this subject (Cameron and Trope, 2004; Trope and Thompson, 1997), we used anonymous targets and did not refer to any social category that was likely to activate strong a priori 
beliefs. In this case, social stereotypes and category expectations are not likely to enhance the $\mathrm{p}(\mathrm{H})$ toward confirmation or falsification. Two traits were used to control for possible content effects. The order of traits and respective targets was properly balanced.

Before beginning the task, participants were asked to estimate the a priori likelihood $(\mathrm{p}(\mathrm{H}))$ that a person randomly chosen from the population would have such characteristics (i.e., cheerfulness/creativity). Participants were then instructed to make an inference with respect to the specific trait after reading a set of 5 pertinent questions asked of Mr. X/ Mr. Y with the corresponding answers ("yess"/“no"). For example, for the trait of creativity, one question was, "Have you ever patented an invention?" The procedure is illustrated in Figure 1. The set of questions was composed of asymmetric or symmetric questions drawn from the list of pre-tested questions, depending on the experimental condition. Thus, the experimental design consisted of a 2 (type of questions: symmetric vs. asymmetric) x 2 (condition: confirmation vs. falsification) x 2 (trait: cheerfulness vs. creativity) design with the first two variables manipulated between subjects and the last variable manipulated within subjects. The number of "yes" or "no" answers was intended to lead the participant toward hypothesis confirmation or falsification. Above all, the frequency of "yes" or "no" answers was fixed according to the preliminary study such that the total diagnosticities of the symmetric and asymmetric sets were balanced. In the symmetric confirming condition, participants received 3 yes (confirming) and 2 no (disconfirming) mildly diagnostic answers, whereas in the symmetric disconfirming condition, participants received 3 no (disconfirming) and 2 yes (confirming) mildly diagnostic answers. In the asymmetric confirming condition, participants received 1 highly diagnostic yes (confirming) answer and 4 mildly diagnostic no (disconfirming) answers, whereas in the asymmetric disconfirming condition, participants received 1 highly diagnostic yes (disconfirming) answer and 4 mildly diagnostic no (confirming) answers. Participants were randomly assigned to one of the four following experimental conditions: symmetric-confirmation, symmetric-falsification, asymmetricconfirmation, and asymmetric-falsification. It is important to note that we used asymmetric- 
confirming questions in the confirmation condition but asymmetric-disconfirming questions in the falsification condition ${ }^{1}$.

Finally, after receiving the information, participants were required to assess the posterior probability $(\mathrm{p}(\mathrm{H} / \mathrm{D}))$ for $\mathrm{Mr}$. $\mathrm{X} / \mathrm{Y}$ to have the corresponding characteristic. Both the a priori and the posterior probabilities were estimated based on an 11-point scale ranging from $0 \%$ (not possible) to $100 \%$ (certain). At the end of the questionnaire session, participants were thanked for their participation, debriefed, and released.

\section{Results}

The impact of either the symmetric or the asymmetric set of questions and of their relative answers was calculated by subtracting the estimated a priori probability $(\mathrm{p}(\mathrm{H}))$ that a person had the specified characteristic from the estimated probability that the person had such a trait given the evidence, that is $\mathrm{p}(\mathrm{H} \mid \mathrm{D})-\mathrm{p}(\mathrm{H})$. Thus, a score higher than 0 indicated that the information led toward confirmation, and a score lower than 0 indicated that the information led toward disconfirmation.

We carried out a $2 \times 2 \times 2$ ANOVA using question type (symmetric vs. asymmetric) and condition (confirmation vs. falsification) as between-subject variables and trait (cheerfulness vs. creativity). Interestingly for our purpose, the data revealed a significant two-way interaction between question type and condition, $F(1,92)=17.42, p<.001, \eta_{\mathrm{p}}{ }^{2}=.16$ (see Figure 2 ). As the post-hoc analyses showed, the symmetric questions and the asymmetric questions had different impacts on impression formation in the confirmation condition, $t(47)=4.09, p<.001, d=1.17$. Specifically, the one-sample $t$-test used to compare the means with the 0 (i.e., the point of indifference) revealed that in the confirmation condition the symmetric questions $(M=7.29, S D=$ 15.39) coherently led participants toward hypothesis support, $t(23)=2.32, p=.03$, whereas the asymmetric questions $(M=-10.4, S D=14.85)$ led to a paradoxical disconfirmation effect, $t(24)=$ $3.50, p=.002$. 
The difference between the impact of symmetric and asymmetric questions in the disconfirming condition is marginally significant, $t(46)=1.71, p=.09, d=0.50$ : whereas the symmetric questions $(M=-6.40, S D=10.16)$ led toward hypothesis falsification, $t(24)=-3.15, p=$ .004 , the asymmetric questions $(M=-0.22, S D=14.73)$ had no impact, $t(23)=-0.07, p=.94$,

The different impacts of symmetric $(M=0.45, S D=1.99)$ and asymmetric questions $(M=$ $5.31, S D=2.04$ ) in the two conditions (confirming vs. disconfirming) justify the main effect of question type, $F(1,92)=4.06, p=.05, \eta_{\mathrm{p}}{ }^{2}=.04$. Condition had no effect, $F(1,92)=.38, p=.54$.

To test the reliability of such an effect in relation to the specific content of the traits used, we explored the impact of the variable trait. ANOVA yielded a main effect of trait, $F(1,92)=$ $58.33, p<.001, \eta_{\mathrm{p}}{ }^{2}=.38$; independently of question type and condition, participants were more likely to judge a social target as creative $(M=8.67, S D=1.98)$ than cheerful $(M=-13.54, S D=$ 2.09). Moreover, the analysis revealed a marginally significant interaction between trait and the remaining two factors, $F(1,92)=3.42, p=.07, \eta_{\mathrm{p}}{ }^{2}=.04$. As the post-hoc analyses showed and consistent with the previous result, the symmetric and asymmetric questions had different impacts on impression formation in the confirming condition (cheerful: $M_{\text {symm }}=-2.50, S D_{\text {symm }}=19.83$; $M_{\text {asymm }}=-25.20, S D_{\text {asymm }}=18.05, p<.001 ;$ creative: $M_{\text {symm }}=17.08, S D_{\text {symm }}=18.76 ; M_{\text {asymm }}=4.40$, $S D_{\text {asymm }}=23.47, p=.02$ ). Conversely, in the disconfirming condition, question type effected impression formation about the target's cheerfulness (cheerful: $M_{\text {symm }}=-19.20, S D_{\text {symm }}=18.69$; $M_{\text {asymm }}=-7.27, S D_{\text {asymm }}=25.10, p=.05$ ) but not about the target's creativity (creative: $M_{\text {symm }}=$ $\left.6.40, S D_{\text {symm }}=16.55 ; M_{\text {asymm }}=6.81, S D_{\text {asymm }}=18.09, p=.84\right)$. The lack of effect in the disconfirming condition for the creativity trait justified the reduced effect of question type in this condition in the global analysis with the two traits collapsed.

No other effects were significant; $F s(1,92)<.66, p s>.42$.

\section{Discussion}

Overall, the results of the first study suggest a complex relationship between the impact of asymmetric information-search strategy and confirmation bias. In fact, the number of confirming 
and disconfirming answers to the questions had greater impact on impressions than the diagnosticities of the answers. Recall that, once assumed that the priors of the trait inquired about are equal (that is, the target does not elicit strong a priori beliefs about the trait under consideration), the confirming answer to an asymmetric-confirming question is highly diagnostic but infrequent, whereas a disconfirming answer is frequent although poorly diagnostic. Thus, the disconfirmatory effect (when the trait inquired about was cheerfulness) or the weak confirmation (when the inquired trait was creativity) of asymmetric-confirming queries might reflect participants' greater sensitivity to the high frequency of the disconfirming answer than to the high diagnosticity of the confirming answer. In other words, the consequence of asymmetric-confirming search was a tendency toward a paradoxical effect, namely, hypothesis falsification. Hence, returning to the example mentioned in introduction, if social perceivers use a series of asymmetric-confirming questions such as "Has s/he ever risked her/his life to save somebody else?" to inquire about an individual's bravery, they will tend to judge the target finally as cowardly. In fact, according to the present findings, the high diagnosticity of rare "yes" answers would not balance the high number of "no" answers.

Although the difference between symmetric and asymmetric questions is clear and consistent across different traits, the same paradoxical effect did not always emerge in the disconfirmation condition. In this case, the difference between symmetric and asymmetricdisconfirming queries regarding their impact on participants' judgments did not arise systematically. This discrepancy between the confirming and disconfirming condition may be due to question phrasing. In fact, in our material, the asymmetric-disconfirming questions were asymmetric-confirming questions on the alternative hypothesis (e.g., 'gloomy' instead of 'cheerful'); moreover, we often used a double negative in the phrasing. For instance, the no-answer to the question “Don't you ever like joking?” would support the trait 'cheerful'. With this phrasing, the cognitive processing required might have been more demanding than when negatives were not used for the asymmetric-confirming questions. Indeed, previous research has shown that people 
experience greater difficulty in processing negative rather than positive information (e.g., Hearst, 1991; Van Wallendael, 1995; Wason, 1959). However, it is worth noting that this limitation does not concern the confirming condition, for which all questions were positively phrased.

\section{Study 2}

In the first study, we calculated the diagnosticity of the questions assuming that each question-answer combination was independent. We carefully balanced the total answer diagnosticity between sets of questions but neglected the possible interdependency of the answers within each set ${ }^{2}$. However, in everyday life, people are quite likely to be affected by prior evidence while evaluating new information (e.g., Hogarth \& Einhorn, 1992) when the data pertain to the same hypothesis and the same target, as in this case. For instance, our estimated probability that a person likes colors could depend on knowing or not knowing whether the individual concerned has an artistic interest.

Therefore, to avoid this possible confounder, we attempted to replicate the results of the first study by changing the paradigm. In the first study, we asked 5 different questions to the same social target to verify a particular individual trait; however, in the second study, we posed the same (either symmetric or asymmetric) question to 10 different members of a group.

\section{Participants}

Sixty undergraduate students at the University of Milano-Bicocca and at the University of Varese volunteered to participate in the study. The sample consisted of $33.1 \%$ women and $66.9 \%$ men, ranging in age from 22 to $58(M=32.53, S D=6.72)$. All participants were Italian citizens.

\section{Material and procedure}

Participants were approached in various libraries and invited to participate in a study about social perception. Those people who accepted were given a questionnaire to fill out. We collected personal data about the participant on the cover page. 
The task consisted of assessing to what degree an unidentified social category, namely category $\mathrm{X}$, was creative and to what degree a second category, $\mathrm{Y}$, was cheerful. The order of traits and respective targets was properly balanced.

Participants were instructed to make an inference regarding the trait after reading the answers to a single question produced by 10 persons selected from an unspecified social category. The procedure is illustrated in Figure 3. The question was asymmetric or symmetric depending on the experimental condition. As in Study 1, the number of "yes" or "no" answers was established to lead the participant toward hypothesis confirmation or falsification and care was taken to ensure that the total diagnosticity was balanced between sets. Thus, the experimental design consisted of a 2 (question type: symmetric vs. asymmetric) x 2 (condition: confirmation vs. falsification) $\mathrm{x} 2$ (trait: cheerful vs. creative) design; the first two variables were manipulated between subjects and the last variable was manipulated within subjects. To balance the total diagnosticity, participants received 9 yes (confirming) and 1 no (disconfirming) mildly diagnostic answers in the symmetric confirming condition but 2 highly diagnostic yes (confirming) answers and 8 mildly diagnostic no (disconfirming) answers in the asymmetric confirming condition. Participants received 8 no (disconfirming) and 2 yes (confirming) mildly diagnostic answers in the symmetric disconfirming condition but 2 highly diagnostic yes (disconfirming) answers and 8 mildly diagnostic no (confirming) answers in the asymmetric disconfirming condition. Participants were randomly assigned to one of the four experimental conditions.

Finally, after receiving the information, participants were required to infer (a) the probability for an individual randomly chosen from category $\mathrm{X} / \mathrm{Y}$ to have the given characteristic and (b) the number of members of the group possessing the trait. Participants answered both questions on a 7point scale ranging from 1 (not likely/few) to 7 (very likely/many). At the end of the questionnaire session, participants were thanked for their participation, debriefed, and released.

\section{Results}


After verifying that the measure of inference about a category member and the measure of generalization were highly correlated with respect to both the creative $(\alpha=.80)$ and cheerful $(\alpha=$ .87 ) traits, we averaged the two items on a composite score. We carried out a $2 \times 2 \times 2$ ANOVA using question type (symmetric vs. asymmetric) and condition (confirmation vs. falsification) as betweensubject variables and trait (cheerful vs. creative) as a within-subject variable.

Consistent with the previous experiment, the data revealed a significant two-way interaction between question type and condition, $F(1,56)=22.22, p<.001, \eta_{\mathrm{p}}{ }^{2}=.28$ (see Figure 4 ). As revealed by post-hoc comparisons, participants were more likely in the confirmation condition to attribute the trait to the category after receiving the answers to a symmetric question $(M=4.90, S D$ $=1.11)$ rather than an asymmetric question $(M=3.18, S D=1.18), t(28)=4.10, p<.001, d=1.15$. Conversely, participants were less likely in the disconfirmation condition to associate the trait with the category after receiving the answers to a symmetric question $(M=3.53, S D=.86)$ rather than an asymmetric question $(M=4.33, S D=.95), t(28)=2.41, p=.02, d=0.88$. Furthermore, a series of one-sample $t$-tests computed to compare participant inferences in the four experimental conditions with the midpoint of the scale (i.e., 4) revealed that the sets of answers effectively drove participants toward confirmation or disconfirmation, $t s(15)<2.10$, $p s<.05$, with the exception of the set of disconfirming answers to the asymmetric question, $t(15)=1.36, p=.19$.

As in Study 1, the different impact of symmetric $(M=4.21, S D=1.36)$ and asymmetric questions $(M=3.76, S D=1.47)$ in the two different conditions (confirming vs. disconfirming) justified a marginal effect of question type, $F(1,56)=2.95, p=.09, \eta_{\mathrm{p}}{ }^{2}=.05$. Condition had no effect, $F(1,56)=.16, p=.69$.

Analogously to the previous study, we explored the impact of the variable trait. In this second study, the use of ANOVA did not yield a main effect of trait, $F(1,56)=1.85, p=.18$, but there was marginally significant interaction effect between trait and the two other factors, $F(1,56)$ $=2.93, p=.09, \eta_{\mathrm{p}}{ }^{2}=.05$. As shown by the post-hoc analyses and consistent with the previous results, the symmetric and asymmetric questions had different impacts on impression formation in 
the confirming condition for both of the traits (creative: $M_{\text {symm }}=4.93, S D_{\text {symm }}=1.24 ; M_{\text {asymm }}=2.53$, $S D_{\text {asymm }}=1.29, p<.001 ;$ cheerful: $M_{\text {symm }}=4.87, S D_{\text {symm }}=1.12 ; M_{\text {asymm }}=3.83, S D_{\text {asymm }}=1.53, p=$ .03). Conversely, there was a greater tendency for question type to affect impression formation about the target's cheerfulness $\left(M_{\text {symm }}=3.47, S D_{\text {slymm }}=1.22 ; M_{\text {asymm }}=4.30, S D_{\text {asymm }}=1.21, p=.08\right)$ than that about the target's creativity $\left(M_{\text {symm }}=3.60, S D_{\text {symm }}=1.23 ; M_{\text {asymm }}=4.37, S D_{\text {asymm }}=1.27, p\right.$ $=.10)$ in the disconfirming condition.

\section{Discussion}

The results of the second study are closely consistent with those of the first study, despite the change in the paradigm. Participants were more prone to associate or dissociate the traits to the social category in the symmetric condition than in the asymmetric condition. More explicitly, they tended to develop social inferences on the basis of the number of the answers (which is relatively high in the symmetric condition) regardless of the data diagnosticity (which is mild). Asymmetricconfirming questions are associated with a high frequency of disconfirming answers and a low frequency of highly diagnostic confirming answers whenever the priors are equal. We found that the effect of this search strategy is both unlikely to lead to hypothesis confirmation and likely to foster hypothesis falsification. Consistent with Study 1, although the effect weakened in the disconfirming condition, answers to the symmetric question had greater impact on the inference process than answers to the asymmetric question. Again, this pattern supports the idea that the number of (disconfirming) answers has a stronger effect than their diagnosticity.

\section{General Discussion}

People's tendency to focus on a working hypothesis and adopt pseudodiagnostic strategies in information gathering is a robust result found in the literature (e.g., Klayman, 1995; Klayman \& Ha, 1987; Nickerson, 1998; Skov \& Sherman, 1986; Slowiaczek, et al., 1992; Wason, 1960, 1968). Furthermore, social-cognitive studies have consistently demonstrated that, while investigating social targets, people prefer questions that match the trait under analysis rather than those that inquire about non-focal traits (e.g., Hodgins \& Zuckerman, 1993; Skov \& Sherman, 1986). In some 
cases, people even ask asymmetric questions for which the separate answers (i.e., "yes" and "no") are neither equally diagnostic nor equally likely (e.g., Cameron \& Trope, 2004; Trope \& Liberman, 1996; Trope \& Thompson, 1997). Although research has clarified that positive testing while searching for information does not necessarily lead to a confirmation bias (Klayman \& Ha, 1987), the relationship between an asymmetric information search and confirmation bias remains ambiguous. In fact, the use of an asymmetric strategy while gathering information might imply a trade-off between the diagnosticity and frequency of the anticipated answers (e.g., McKenzie, 2006; Poletiek, 2001; Poletiek \& Berndsen, 2000). For this reason, we investigated the impact that an asymmetric information search about a social target could have on the final impression. Two experimental studies found notably consistent results. Overall, these results suggested that participants interpreted asymmetric testing outcomes more in terms of their frequency than diagnosticity. In fact, in the confirmation condition, symmetric questions which received more yes (confirming) than no (disconfirming) answers, even if mildly diagnostic, were likely to confirm the hypothesis. In contrast, asymmetric questions, which received only one highly diagnostic yes (confirming) answer, were likely to falsify it. Thus, people who adopt an asymmetric informationsearch strategy looking for extreme and conclusive pieces of information could incur a paradoxical effect.

This result suggests that the choice of an asymmetric rather than a symmetric informationsearch strategy might have relevant effects on social perception when strong a priori beliefs are not involved (that is, whenever the hypothesis being tested has a prior probability not very different from $p=0.5$ ). Interestingly, the same pattern arose when participants were presented with answers to different questions pertaining to an individual's personality trait (Study 1) and when they were presented with answers given by different group members to the same question (Study 2). In other words, the consequences of symmetric and asymmetric information search on trait attribution follow the same pattern regardless of whether the context of the judgment is interpersonal or at group level. In both studies, the target of the inquiries were not identified (i.e., Mr. X/Y in Study 1, 
Category $\mathrm{X} / \mathrm{Y}$ in Study 2) and the traits inquired about (i.e., creativity and cheerfulness) did not have extreme prior probability of occurrence. Therefore, the question of whether motivational factors and previous knowledge might play a role and differentiate between the consequences of symmetric and asymmetric information search as a function of the type of social interaction (interpersonal vs. intergroup) deserves empirical investigation.

Overall, the findings of the present studies are consistent with the findings of Skov and Sherman (1986; Slowiaczek et al., 1992), who concluded that people were relatively insensitive to answer diagnosticity but sensitive to answer frequency (the number of "yes" and "no" answers they receive). The findings also dovetail nicely with the theory of decision by sampling (Stewart, Chater, \& Brown, 2006). According to this model, people's judgments in several domains are based on a tally of the number of exemplars drawn from memory that favor or contradict a target attribute, and the sample of exemplars on which this tally is based reflects the real-world distributions. In a similar way, the results of our experiments show that people base their impressions on the tally of the number of confirming vs. disconfirming answers to a question rather than on the diagnosticity of the individual answers. Furthermore, the results of the present studies echo the frequency-based accounts of illusory correlations in social contexts (e.g., Fiedler, 1991, 1996). Finally, the present findings are consistent with a tendency found by Rusconi et al. (2012) on people's expectations about symmetric and asymmetric information searching. In Rusconi et al. (2012), participants exhibited a tendency to provide higher probability estimates of receiving a confirming answer following an asymmetric-disconfirming question than after an asymmetric-confirming question. Thus, the participants showed that they were more influenced in their judgments by a frequent confirming answer (that follows asymmetric-disconfirming queries) rather than by a diagnostic confirming answer (that follows asymmetric-confirming queries). However, future studies are in need to explore the boundary conditions and to determine the different proportions of "yes"/ "no" answers in symmetric vs. asymmetric condition which are likely to elicit the effect. 
Whereas the results consistently revealed that answers to symmetric questions had a greater effect on impression formation than did answers to asymmetric questions in the disconfirming condition, the paradoxical effect was not observed. Thus, whereas the set of symmetric questions weakened the hypothesis likelihood, the asymmetric disconfirming set had no effect. As we noted above, this lack of an effect on participants' judgments of asymmetric-disconfirming queries may be due to question phrasing, specifically to the use of double negatives. Future studies using different materials might attempt to overcome this asymmetrical processing underlying the two types of asymmetric questions. To attain a more comprehensive picture, it would be useful to adopt a more complete experimental design that provides a confirming set of answers to asymmetricdisconfirming questions and a disconfirming set of answers to asymmetric-confirming questions.

Although our results suggested a paradoxical effect, we cannot confirm that people are indeed likely to falsify their a priori social beliefs through a confirming asymmetric search. According to a more recent approach to confirmation bias, this would originate from the interaction of multiple processes rather than from one specific stage of the hypothesis development (e.g., Klayman, 1995; McKenzie, 2004, 2006; Nickerson, 1998; Poletiek, 2001; Slowiaczek et al., 1992; Zuckerman, Knee, Hodgins, \& Miyake, 1995). Hence, if the asymmetric search, per se, does not lead to social expectancy confirmation, it could effectively interact with the following stage, namely, the information encoding stage, where the confirming evidence could carry greater weight than the disconfirming information (e.g., Johnston, 1996). Moreover, the consequence of a particular information search strategy might be affected by the stopping rule; that is, the number of pieces of evidence the information seeker obtains before stopping the search (e.g., Stigler, 1961). If an asymmetric and restricted search strategy is employed, the amount of disconfirming information encountered through an asymmetric-confirming search will be limited and the risk of a boomerang effect will be significantly reduced.

Furthermore, empirical investigations are needed to test the hypothesized lack of a frequency/diagnosticity trade-off in the presence of strong a priori beliefs, for instance, when the 
social target is stereotyped and the expectation that $\mathrm{s} / \mathrm{he}$ exhibits the examined trait is therefore high (e.g., Trope \& Thompson, 1997). From a Bayesian perspective, a high prior probability of the hypothesis being tested causes the hypothesis-confirming answer to be both highly frequent and highly diagnostic; despite this, whether people behave in keeping with this Bayesian tenet has never been tested. For these reasons, future studies should aim at exploring the presence of the trade-off between diagnosticity and frequency in a/symmetric information gathering and its consequences not only on neutral and anonymous social targets (as in the present contribution) but also on specific social categories in which stereotypes could affect the process and motivational variables (such as the intergroup bias) could play an important role (e.g., Sacchi et al., 2012). 


\section{References}

Bassok, M., \& Trope, Y. (1984). People's strategies for testing hypothesis about another's personality: Confirmatory or diagnostic? Social Cognition, 2, 199-216. doi:10.1521/soco.1984.2.3.199

Brambilla, M., Rusconi, P., Sacchi, S., \& Cherubini, P. (2011). Looking for honesty: The primary role of morality (vs. sociability and competence) in information gathering. European Journal of Social Psychology, 41, 135-143. doi: 10.1002/ejsp.744

Cameron, J. A., \& Trope, Y. (2004). Stereotype-biased search and processing of information about group members. Social Cognition, 22, 650-672. doi: 10.1521/soco.22.6.650.54818

Cherubini, P., Rusconi, P., Russo, S., Di Bari, S., \& Sacchi, S. (2010). Preferences for different questions when testing hypotheses in an abstract task: Positivity does play a role, asymmetry does not. Acta Psychologica, 134, 162-174. doi:10.1016/j.actpsy.2010.01.007

Dardenne, B., \& Leyens, J.-Ph. (1995). Confirmation bias as a social skill. Personality and Social Psychology Bulletin, 21, 1229-1239. doi:10.1177/01461672952111011

Devine, P. G., Hirt, E. R., \& Gehrke, E. M. (1990). Diagnostic and confirmation strategies in trait hypothesis testing. Journal of Personality and Social Psychology, 58, 952-963. doi: $10.1037 / 0022-3514.58 .6 .952$

Fiedler, K. (1991). The tricky nature of skewed frequency tables: An information loss account of distinctiveness-based illusory correlations. Journal of Personality and Social Psychology, 60, 24-36. doi:10.1037//0022-3514.60.1.24

Fiedler, K. (1996). Explaining and simulating judgment biases as an aggregation phenomenon in probabilistic, multiple-cue environments. Psychological Review, 103, 193-214. doi:10.1037//0033-295X.103.1.193

Fiedler, K., \& Walther, E. (2004). Stereotyping as inductive hypothesis testing. Hove, U.K.: Psychology Press. 
Fischhoff, B., \& Beyth-Marom, R. (1983). Hypothesis evaluation from a Bayesian perspective. Psychological Review, 90, 239-260. doi:10.1037//0033-295X.90.3.239

Fiske, S. T. (1980). Attention and weight in person perception: The impact of negative and extreme behavior. Journal of Personality and Social Psychology, 38, 889-906. doi:10.1037//00223514.38.6.889

Hearst, E. (1991). Psychology and nothing. American Scientist, 79, 432-443.

Hodgins, H. S., \& Zuckerman, M. (1993). Beyond selecting information: Biases in spontaneous questions and resultant conclusions. Journal of Experimental Social Psychology, 29, 387407. doi: 10.1006/jesp.1993.1018

Hogarth, R. M., \& Einhorn, H. J. (1992). Order effects in beliefs updating: The belief-adjustment model. Cognitive Psychology, 24, 1-55. doi:10.1016/0010-0285(92)90002-J

Johnston, L. (1996). Resisting change: Information seeking and stereotype change. European Journal of Social Psychology, 26, 799-826. doi:10.1002/(SICI)10990992(199609)26:5<799::AID-EJSP796>3.3.CO;2-F

Klayman, J. (1995). Varieties of confirmation bias. The Psychology of Learning and Motivation, 32, 385-418. doi: 10.1016/S0079-7421(08)60315-1

Klayman, J., \& Ha, Y. W. (1987). Confirmation, disconfirmation, and information in hypothesis testing. Psychological Review, 94, 211-228. doi: 10.1037/0033-295X.94.2.211

McKenzie, C. R. M. (2004). Hypothesis testing and evaluation. In D. J. Koehler \& N. Harvey (Eds.), Blackwell handbook of judgment and decision making (pp. 200-219). Malden, MA, US: Blackwell Publishing.

McKenzie, C. R. M. (2006). Increased sensitivity to differentially diagnostic answers using familiar materials: Implications for confirmation bias. Memory \& Cognition, 34, 577-588. doi:10.3758/BF03193581

Nelson, J. D. (2005). Finding useful questions: On Bayesian diagnosticity, probability, impact, and information gain. Psychological Review, 112, 979-999. doi: 10.1037/0033-295X.112.4.979 
Nelson, J. D. (2008). Towards a rational theory of human information acquisition. In N. Chater \& M. Oaksford (Eds.), The probabilistic mind: Prospects for Bayesian cognitive science (pp. 143-163). Oxford, UK: Oxford University Press.

Nickerson, R. S. (1998). Confirmation bias: A ubiquitous phenomenon in many guises. Review of General Psychology, 2, 175-220. doi: 10.1037/1089-2680.2.2.175

Oaksford, M., \& Chater, N. (1994). A rational analysis of the selection task as optimal data selection. Psychological Review, 101, 608-631.

Poletiek, F. [H.] (2001). Hypothesis-testing behaviour. Hove, U.K.: Psychology Press.

Poletiek, F. H., \& Berndsen, M. (2000). Hypothesis Testing as Risk Behaviour with Regard to Beliefs. Journal of Behavioral Decision Making, 13, 107-123. doi: 10.1002/(SICI)10990771(200001/03)13:1<107::AID-BDM349>3.0.CO;2-P

Rusconi, P., Sacchi, S., Toscano, A., \& Cherubini, P. (2012). Confirming expectations in asymmetric and symmetric social hypothesis testing. Experimental Psychology, 59, 243-250. doi: 10.1027/1618-3169/a000149

Sacchi, S., Rusconi, P., Russo, S., Bettiga, R., \& Cherubini, P. (2012). New knowledge for old credences: Asymmetric information search about in-group and out-group members. British Journal of Social Psychology, 51, 606-625. doi: 10.1111/j.2044-8309.2011.02026.x

Skov, R. B., \& Sherman, S. J. (1986). Information-gathering processes: Diagnosticity, hypothesisconfirmatory strategies, and perceived hypothesis confirmation. Journal of Experimental Social Psychology, 22, 93-121. doi: 10.1016/0022-1031(86)90031-4

Stigler, G. J. (1961). The Economics of Information. The Journal of Political Economy, 69, 213225. doi:10.1086/258464

Slowiaczek, L. M., Klayman, J., Sherman, S. J., \& Skov, R. B. (1992). Information selection and use in hypothesis testing: What is a good question, and what is a good answer? Memory \& Cognition, 20, 392-405. doi:10.3758/BF03210923 
Snyder, M., \& Swann, W. B. (1978). Hypothesis-testing processes in social interaction. Journal of Personality and Social Psychology, 36, 1202-1212. doi:10.1037/0022-3514.36.11.1202

Stewart, N., Chater, N., \& Brown, G. D. A. (2006). Decision by sampling. Cognitive Psychology, 53, 1-26. doi: 10.1016/j.cogpsych.2005.10.003

Tribus, M. (1961). Thermostatics and thermodynamics: An introduction to energy, information and states of matter, with engineering applications. Princeton, NJ: D. van Nostrand Company, Inc.

Trope, Y., \& Bassok, M. (1983). Information-gathering strategies in hypothesis-testing. Journal of Experimental Social Psychology, 19, 560-576. doi: 10.1016/00221031(83)90016-1

Trope, Y., \& Liberman, A. (1996). Social hypothesis-testing: Cognitive and motivational mechanisms. In E. T. Higgins \& A. W. Kruglanski (Eds.), Social psychology: Handbook of basic principles (pp. 239-270). New York: Guilford Press.

Trope, Y., \& Thompson, E. P. (1997). Looking for truth in all the wrong places? Asymmetric search of individuating information about stereotyped group members. Journal of Personality and Social Psychology, 73, 229-241. doi: 10.1037/0022-3514.73.2.229

Van Avermaet, E. (1988). Testing hypothesis about other people: Confirmatory and diagnostic strategies. Communication and Cognition, 21, 179-189.

Van Wallendael, L. R. (1995). Implicit diagnosticity in an information-buying task. How do we use the information that we bring with us to a problem? Journal of Behavioral Decision Making, 8, 245-264. doi:10.1002/bdm.3960080403

Wason, P. C. (1959). The processing of positive and negative information. Quarterly Journal of Experimental Psychology, 11, 92-107. doi:10.1080/17470215908416296

Wason, P. C. (1960). On the failure to eliminate hypotheses in a conceptual task. The Quarterly Journal of Experimental Psychology, 12, 129-140. doi:10.1080/17470216008416717

Wason, P. C. (1968). Reasoning about a rule. The Quarterly Journal of Experimental Psychology, 20, 273-281. doi: 10.1080/14640746808400161 
Yzerbyt, V. Y., \& Leyens, J.-Ph. (1991). Requesting information to form an impression: The influence of valence and confirmatory status. Journal of Experimental Social Psychology, 27, 337-356. doi: 10.1016/0022-1031(91)90030-A

Zuckerman, M., Knee, C. R., Hodgins, H. S., \& Miyake, K. (1995). Hypothesis confirmation: The joint effect of positive test strategy and acquiescence response set. Journal of Personality and Social Psychology, 68, 52-60. doi: 10.1037/0022-3514.68.1.52 


\section{Footnotes}

${ }^{1}$ Note that, potentially, one can confirm a hypothesis also through asymmetric-disconfirming questions and falsify it through asymmetric-confirming questions.

${ }^{2}$ To stem this problem and to control for the evidence interdependency, we should be able to assess and to balance all the possible combinations of the conditional probabilities. This procedure is not feasible. 
Tables

Table 1

Sets of questions (with the relative asymmetry indices) and answers (with the relative

informativeness indices) selected for Study 1 by experimental conditions. In Italian in the original

text.

\begin{tabular}{|c|c|c|c|c|c|c|c|}
\hline \multicolumn{8}{|l|}{ Trait: creative } \\
\hline \multicolumn{4}{|c|}{ Symmetric confirming } & \multicolumn{4}{|c|}{ Symmetric disconfirming } \\
\hline Questions & Asym. & Answers & Inform. & Questions & Asym. & Answers & Inform. \\
\hline $\begin{array}{l}\text { Do you have } \\
\text { imagination? }\end{array}$ & 3.20 & Yes & 31.60 & $\begin{array}{l}\text { Do you like } \\
\text { photography? }\end{array}$ & 8.00 & Yes & 15.60 \\
\hline Do you have hobbies? & -7.60 & Yes & 4.00 & Do you like colors? & -7.20 & Yes & 0.00 \\
\hline $\begin{array}{l}\text { Do you play an } \\
\text { instrument? }\end{array}$ & 6.00 & Yes & 10.40 & $\begin{array}{l}\text { Have you several } \\
\text { interests? }\end{array}$ & 0.80 & No & -14.40 \\
\hline $\begin{array}{l}\text { Are you interested in } \\
\text { art? }\end{array}$ & 8.00 & No & -10.80 & $\begin{array}{l}\text { Do you play an } \\
\text { instrument? }\end{array}$ & 6.00 & No & -4.40 \\
\hline $\begin{array}{l}\text { Do you like } \\
\text { photography? }\end{array}$ & 8.00 & No & -7.60 & $\begin{array}{l}\text { Do you cook as a } \\
\text { hobby? }\end{array}$ & 9.20 & No & -3.60 \\
\hline TOTAL & & & 27.60 & TOTAL & & & -6.80 \\
\hline \multicolumn{4}{|c|}{ Asymmetric confirming } & \multicolumn{4}{|c|}{ Asymmetric disconfirming } \\
\hline Questions & Asym. & Answers & Inform. & Questions & Asym. & Answers & Inform. \\
\hline $\begin{array}{l}\text { Have you ever } \\
\text { patented an invention? }\end{array}$ & 32.40 & Yes & 37.60 & $\begin{array}{l}\text { Do you never have } \\
\text { original ideas? }\end{array}$ & -20.00 & Yes & -31.20 \\
\hline Are you a musician? & 12.00 & No & -3.20 & $\begin{array}{l}\text { Do you completely } \\
\text { lack imagination? }\end{array}$ & -26.00 & No & 5.20 \\
\hline Are you a spray artist? & 25.60 & No & -2.80 & $\begin{array}{l}\text { finding ingenious } \\
\text { solutions? }\end{array}$ & -23.20 & No & 6.00 \\
\hline $\begin{array}{l}\text { Have you attended } \\
\text { design courses? }\end{array}$ & 19.20 & No & -2.00 & $\begin{array}{l}\text { Do you think the art } \\
\text { to be futile? }\end{array}$ & -16.40 & No & 6.00 \\
\hline Do you write books? & 21.60 & No & -2.40 & $\begin{array}{l}\text { Do you use } \\
\text { mechanical } \\
\text { procedures? }\end{array}$ & -14.00 & No & 6.40 \\
\hline TOTAL & & & 27.20 & TOTAL & & & -7.60 \\
\hline
\end{tabular}

Trait: cheerful

\begin{tabular}{|c|c|c|c|c|c|c|c|}
\hline \multicolumn{4}{|c|}{ Symmetric confirming } & \multicolumn{4}{|c|}{ Symmetric disconfirming } \\
\hline Questions & Asym. & Answers & Inform. & Questions & Asym. & Answers & Inform. \\
\hline $\begin{array}{l}\text { Do you like going out } \\
\text { with friends? }\end{array}$ & -4.00 & Yes & 14.80 & $\begin{array}{l}\text { Do you like buying } \\
\text { gifts? }\end{array}$ & -5.60 & Yes & 4.00 \\
\hline $\begin{array}{l}\text { Do you like lively } \\
\text { people? }\end{array}$ & -7.60 & Yes & 6.40 & $\begin{array}{l}\text { Do you like lively } \\
\text { people? }\end{array}$ & -7.60 & Yes & 6.40 \\
\hline $\begin{array}{l}\text { Do you like buying } \\
\text { gifts? }\end{array}$ & -5.60 & Yes & 4.00 & $\begin{array}{l}\text { Do you like going } \\
\text { out with friends? }\end{array}$ & -4.00 & No & -18.80 \\
\hline $\begin{array}{l}\text { Do you buttonhole } \\
\text { people? }\end{array}$ & 1.20 & No & -13.60 & $\begin{array}{l}\text { Do you buttonhole } \\
\text { people? }\end{array}$ & 1.20 & No & -13.60 \\
\hline $\begin{array}{l}\text { Do you celebrate } \\
\text { carnival? }\end{array}$ & 8.00 & No & -3.60 & $\begin{array}{l}\text { Do you celebrate } \\
\text { carnival? }\end{array}$ & 8.00 & No & -3.60 \\
\hline TOTAL & & & 8.00 & TOTAL & & & -25.60 \\
\hline
\end{tabular}




\begin{tabular}{|c|c|c|c|c|c|c|c|}
\hline \multicolumn{4}{|c|}{ Asymmetric confirming } & \multicolumn{4}{|c|}{ Asymmetric disconfirming } \\
\hline Questions & Asym. & Answers & Inform. & Questions & Asym. & Answers & Inform. \\
\hline $\begin{array}{l}\text { Do you often organize } \\
\text { parties? }\end{array}$ & 29.20 & Yes & 30.80 & $\begin{array}{l}\text { Do you consider } \\
\text { idleness a waste of } \\
\text { time? }\end{array}$ & -24.17 & Yes & -37.40 \\
\hline $\begin{array}{l}\text { Dou you love singing } \\
\text { with friends? }\end{array}$ & 13.60 & No & -2.00 & Are you always sad? & -28.33 & No & 0.03 \\
\hline $\begin{array}{l}\text { Are you the 'soul' of } \\
\text { the parties? }\end{array}$ & 25.60 & No & -5.60 & $\begin{array}{l}\text { Do you never like } \\
\text { being in company? }\end{array}$ & -32.92 & No & 0.87 \\
\hline $\begin{array}{l}\text { Do you make the most } \\
\text { of enjoyment every } \\
\text { moment? }\end{array}$ & 21.60 & No & -6.80 & $\begin{array}{l}\text { Do you never take } \\
\text { jokes? }\end{array}$ & -20.87 & No & 5.72 \\
\hline $\begin{array}{l}\text { Do you take even bad } \\
\text { jokes? }\end{array}$ & 12.80 & No & -6.00 & $\begin{array}{l}\text { Can't you stand } \\
\text { hustle and bustle? }\end{array}$ & -14.58 & No & 7.53 \\
\hline TOTAL & & & 10.40 & TOTAL & & & -23.32 \\
\hline
\end{tabular}


Table 2

Questions and answers (with the relative indices) selected for Study 2 by experimental conditions.

In Italian in the original text.

Trait: creative

\begin{tabular}{|c|c|c|c|c|c|c|c|}
\hline \multicolumn{4}{|c|}{ Symmetric confirming } & \multicolumn{4}{|c|}{ Symmetric disconfirming } \\
\hline Question & Asym. & $N$ yes & $N$ no & Question & Asym. & $N$ yes & $N$ no \\
\hline Do you like colors? & -7.20 & 9 & 1 & $\begin{array}{l}\text { Do you like } \\
\text { photography? }\end{array}$ & 8.00 & 2 & 8 \\
\hline \multicolumn{4}{|c|}{ Asymmetric confirming } & \multicolumn{4}{|c|}{ Asymmetric disconfirming } \\
\hline Question & Asym. & $N$ yes & $N$ no & Question & Asym. & $N$ yes & $N$ no \\
\hline $\begin{array}{l}\text { Have you ever } \\
\text { patented an invention? }\end{array}$ & 32.40 & 2 & 8 & $\begin{array}{l}\text { Do you completely } \\
\text { lack imagination? }\end{array}$ & -26.00 & 2 & 8 \\
\hline
\end{tabular}

Trait: cheerful

\begin{tabular}{|c|c|c|c|c|c|c|c|}
\hline \multicolumn{4}{|c|}{ Symmetric confirming } & \multicolumn{4}{|c|}{ Symmetric disconfirming } \\
\hline Question & Asym. & Nyes & $N$ no & Question & Asym. & $N$ yes & $N$ no \\
\hline $\begin{array}{l}\text { Do you like lively } \\
\text { people? }\end{array}$ & -7.60 & 8 & 2 & $\begin{array}{l}\text { Do you enjoy } \\
\text { entertaining? }\end{array}$ & 10.40 & 2 & 8 \\
\hline \multicolumn{4}{|c|}{ Asymmetric confirming } & \multicolumn{4}{|c|}{ Asymmetric disconfirming } \\
\hline Question & Asym. & $N$ yes & $N$ no & Question & Asym. & $N$ yes & $N$ no \\
\hline $\begin{array}{l}\text { Do you often organize } \\
\text { parties? }\end{array}$ & 29.20 & 3 & 7 & $\begin{array}{l}\text { Do you never like } \\
\text { being in company? }\end{array}$ & -32.92 & 3 & 7 \\
\hline
\end{tabular}


Figure captions

Figure 1. Exemplification of the procedure used in Study 1 to present participants with questions and relative answers. In Italian in the original text.

Figure 2. Results from Study 1: The impact of confirming and disconfirming sets of answers to symmetric and asymmetric questions on the attribution of personality traits to a social target. Error bars represent SEMs.

Figure 3. Exemplification of the procedure used in Study 2 to present participants with questions and relative answers. In Italian in the original text.

Figure 4. Results from Study 2: Attribution of the traits to a social category after receiving confirming and disconfirming sets of answers to a symmetric or an asymmetric question. Error bars represent SEMs. 
Figure 1
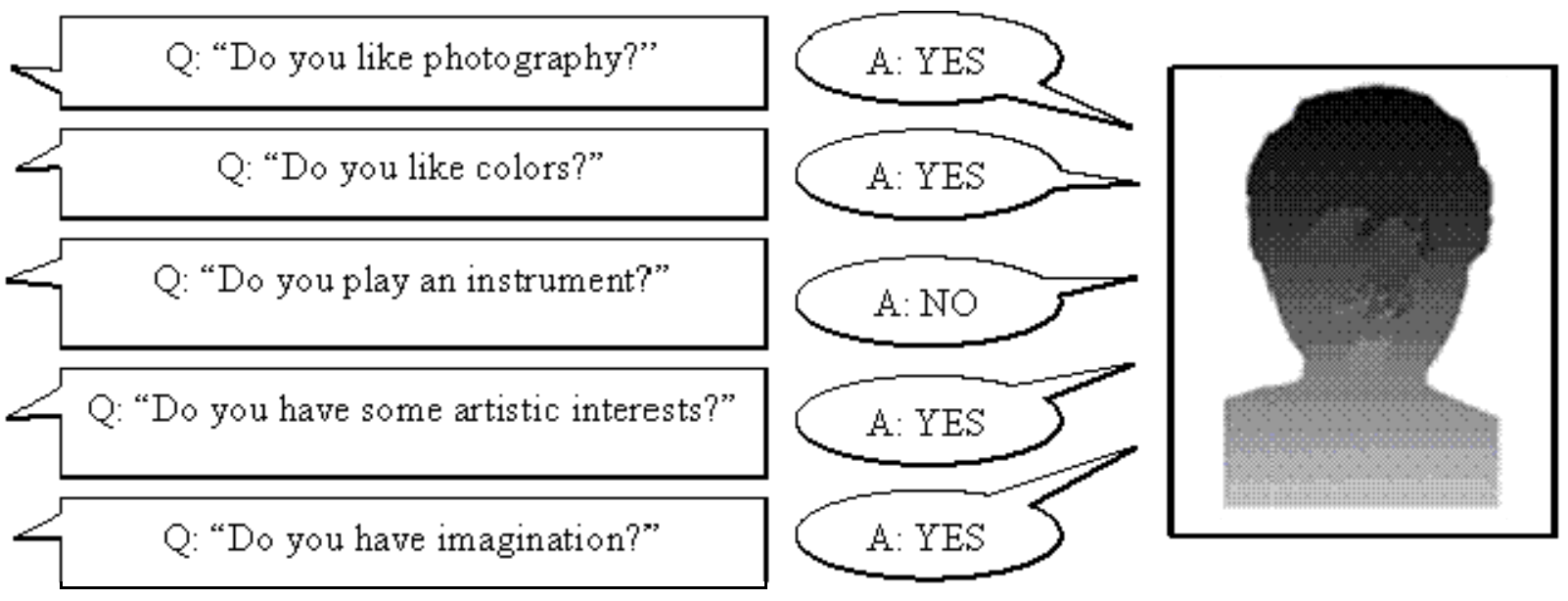
Figure 2.

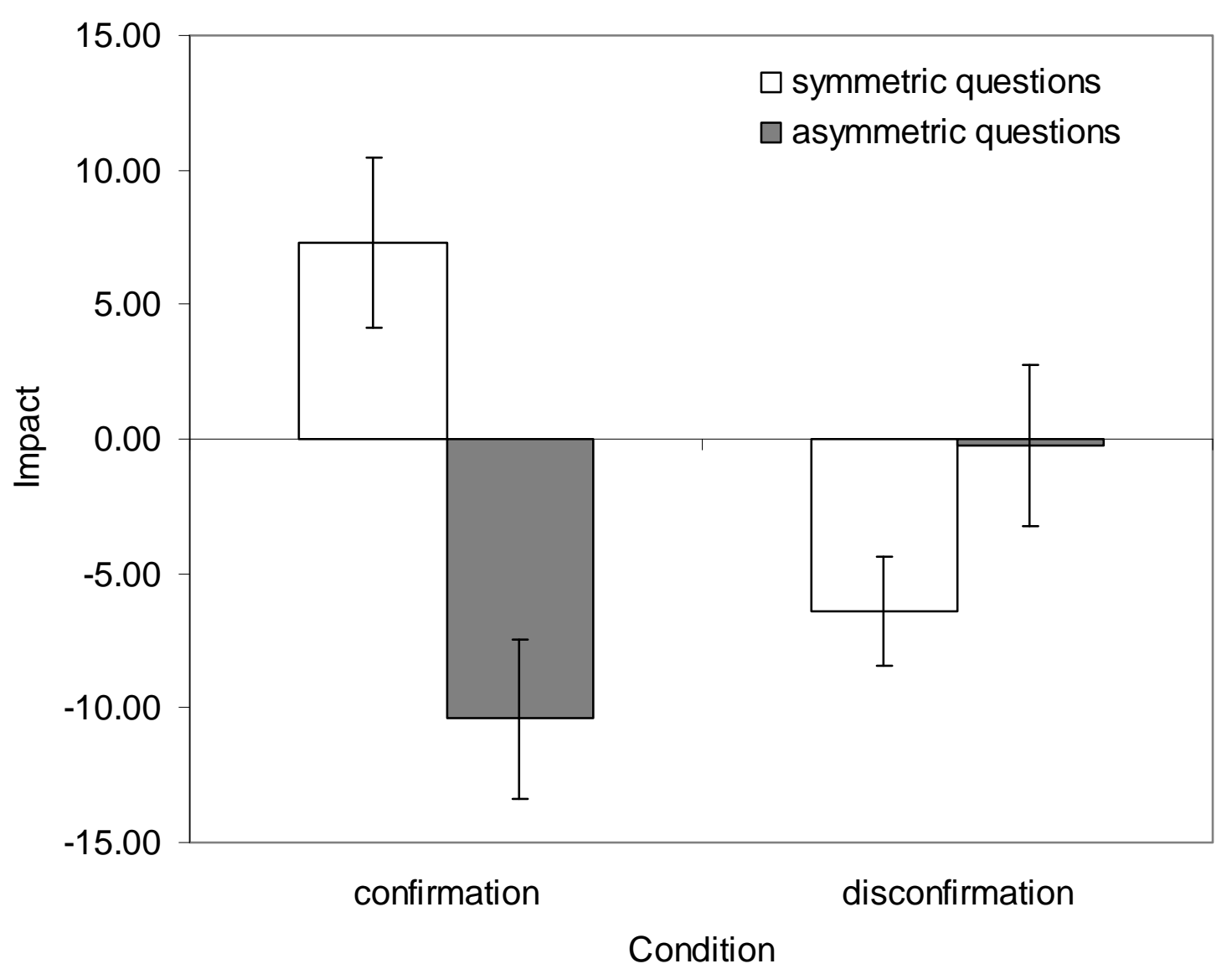


Figure 3.

"Do you like colors?"

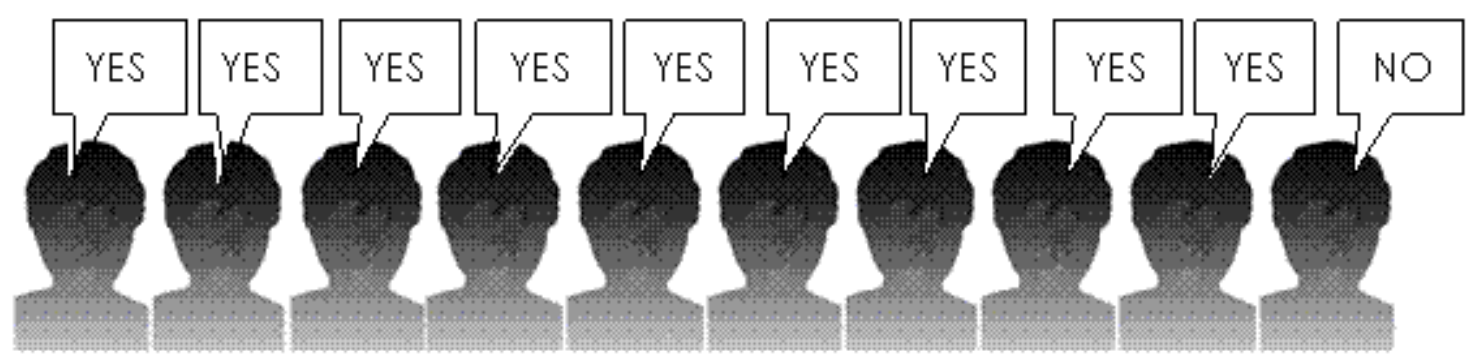


Figure 4.

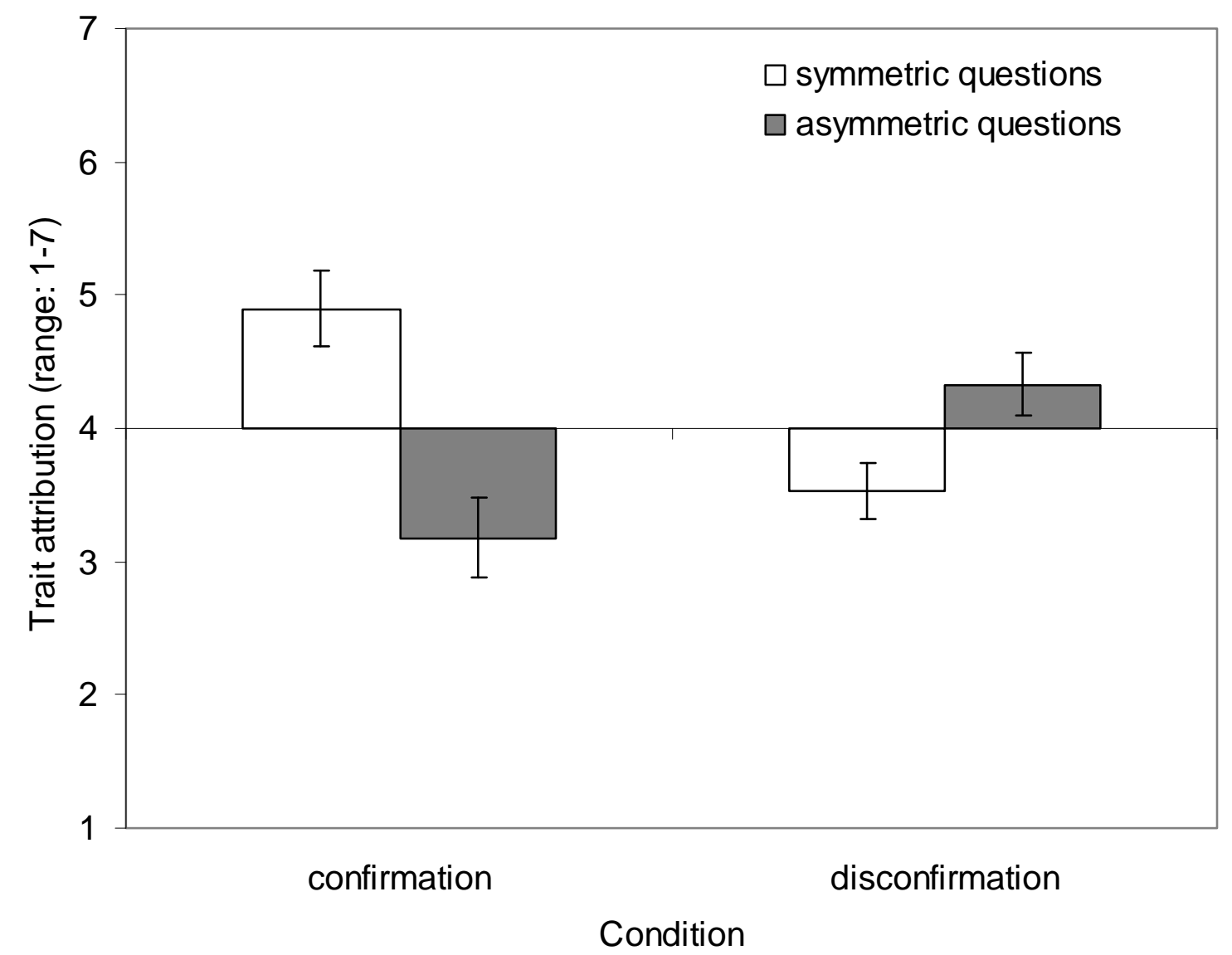

